\title{
An exploratory survey to identify the adolescents with high risk for Polycystic Ovarian Syndrome (PCOS) and to find the effectiveness of an awareness programme among students of selected pre university colleges of Udupi District
}

\author{
Shobha ${ }^{1}$, Elsa Sanatombi Devi ${ }^{2}$, Anusuya Prabhu ${ }^{3}$ \\ ${ }^{1}$ Lecturer Department of OBG Nursing, Manipal College of Nursing Manipal \\ ${ }^{2}$ Professor Department of Medical Surgical Nursing, Manipal College of Nursing Manipal \\ ${ }^{3}$ Assistant professor Department of OBG Nursing Manipal College of Nursing Manipal
}

\begin{abstract}
Introduction: Polycystic Ovarian Syndrome (PCOS) is one of the leading health problems among women of reproductive age group. Many of the menstrual problems are ignored initially during the adolescent period, and the problem will be identified much later when they seek treatment for infertility. Risk assessment appears to be the most useful method in identifying the condition at the earliest and encourage the adolescents for seeking the treatment.
\end{abstract}

Objective: objectives of the study were to identify the adolescents with risk for developing PCOS and to find the effectiveness of awareness program.

Method and materials: the study was conducted in selected pre-university colleges of Udupi District and 752 students were selected from six colleges. Risk Status of the students was assessed by administering the High Risk Assessment questionnaire and awareness program was given to the risk group students, and the post-test was taken on $8^{\text {th }}$ day following intervention.

Results: A total of 102 (13.6\%) students were found to have moderate risk for developing PCOS.A significant increase in the knowledge scores on PCOS was observed after the awareness program ( $p<0.001)$. Conclusion: This study revealed that an awareness program could bring about a desirable change in knowledge among adolescent girls regarding PCOS and prevent future complications.

Key words: adolescent students, awareness programme, Polycystic Ovarian Syndrome (PCOS), pre-university college, risk status.

\section{Introduction}

Polycystic Ovarian Syndrome (PCOS) is one of the most common female endocrine disorders affecting approximately $5-10 \%$ of women of reproductive age (15-45 years) and was thought to be one of the leading causes of female infertility ${ }^{[1]}$. PCOS often manifests around the time of menarche as irregular and often lengthened menstrual cycles. It often goes unrecognized and undiagnosed at this time because most adolescents do not have regular menstrual cycles. In addition, these young women go undiagnosed because the prescribed treatment for irregular menstrual cycles is the use of Oral Contraceptive Pills (OCPs). OCPs will regulate menstrual cycle and often controls acne and hirsutism. Often these girls will not receive a diagnosis until much later, perhaps at the time when they seek treatment for infertility ${ }^{[2]}$. The major purpose of this study is to create awareness among adolescents about PCOS. This will help them to modify their life style and to have better reproductive life. The main objectives of this study were to 1) identify the adolescent girls who are at high risk for PCOS. 2) find association between PCOS risk status with selected variable i.e. socio-economic status. 3) determine the effectiveness of the awareness programme on PCOS in terms of gain in knowledge scores as measured by knowledge questionnaires.

\section{Material and Methods}

The study was conducted in selected pre-university colleges of Udupi District, and 752 students were included in the study. The data were collected by using demographic proforma, risk assessment tool on PCOS to identify the risk status and structured knowledge questionnaire on PCOS to assess the knowledge level of students on PCOS. The study was conducted in two phases; first phase was the survey approach as it aimed to assess the risk status of the adolescents and the second phase was the evaluative approach as it aimed to evaluate the effectiveness of an awareness program on PCOS. The risk status was arbitrarily classified as 0-13 low risk, 14-26 moderate risk and 27-39 high risk. Chi square test was performed using SPSS version 16 to measure the association between risk status and selected variables. 


\section{Results}

2.1 Description of sample characteristics of phase I

Table 1: frequency and percentage distribution of students by sample characteristics

$n=752$

\begin{tabular}{|c|c|c|c|}
\hline SI No. & $\begin{array}{l}\text { Sample Characteristics } \\
\text { Age in vears }\end{array}$ & f & $\%$ \\
\hline & 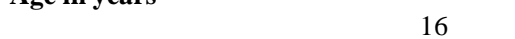 & 253 & 33.7 \\
\hline & 17 & 389 & 51.7 \\
\hline & 18 & 110 & 14.6 \\
\hline 2 & Area of living & & \\
\hline & Urban & 89 & 11.8 \\
\hline & Rural & 663 & 88.2 \\
\hline 3. & Income in rupees & & \\
\hline & $>10000$ & 184 & 24.5 \\
\hline & $5001-10000$ & 360 & 47.9 \\
\hline & $3001-5000$ & 208 & 27.6 \\
\hline 4 & Fathers' educational level & & \\
\hline & Illiterate & 42 & 5.6 \\
\hline & Primary & 353 & 46.9 \\
\hline & High school & 266 & 35.4 \\
\hline & PUC & 64 & 8.5 \\
\hline & Graduate & 22 & 2.8 \\
\hline & postgraduate & 5 & 0.8 \\
\hline 5. & Mothers' educational level & & \\
\hline & Illiterate & 47 & 6.2 \\
\hline & Primary & 437 & 58.1 \\
\hline & High school & 210 & 27.9 \\
\hline & PUC & 46 & 6.1 \\
\hline & Graduate & 11 & 1.6 \\
\hline & postgraduate & 1 & 0.1 \\
\hline 6 & Fathers' occupation & & \\
\hline & Unskilled & 323 & 42.4 \\
\hline & Semiskilled & 242 & 32.0 \\
\hline & Professional & 4 & 0.5 \\
\hline & Business & 182 & 25.1 \\
\hline 7 & Mothers' occupation & & \\
\hline & Unskilled & 94 & 12.5 \\
\hline & Semiskilled & 102 & 13.6 \\
\hline & Professional & 2 & 0.3 \\
\hline & Housewife & 554 & 73.6 \\
\hline 8 & Habit of reading health related magazines & & \\
\hline & Yes & 562 & 74.7 \\
\hline & No & 190 & 25.3 \\
\hline
\end{tabular}

Data in table 1 shows that out of 752 students, 389 (51.7\%) students belonged to the age of 17 years and $253(33.7 \%)$ students belonged to the age of 16 years. Majority, $663(88.2 \%)$ of the students belonged to rural area and $562(74.7 \%)$ of the students had the habit of reading health related magazines. Father's educational status of majority, $353(46.9 \%)$ of the students was primary education and majority, of their mother's educational status 437 (58.1\%) was primary education. Fathers' occupation of majority of the students $323(42.4 \%)$ was unskilled labour and majority, 554 (73.6\%) of the students' mothers were home makers.

\subsection{Risk status of students for PCOS}

Out of 752 students, $650(86.2 \%)$ of the students in the study group had low risk and $102(13.4 \%)$ were at moderate risk for developing PCOS. None of the students had high risk for developing PCOS. 


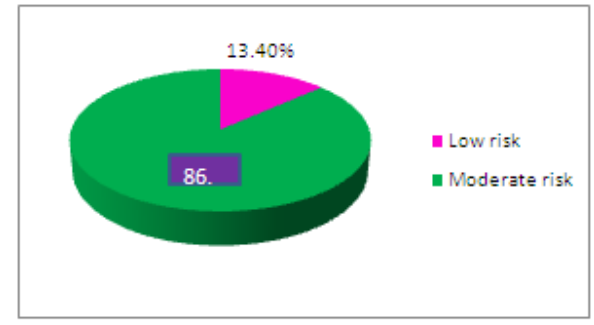

Figl: Risk status of adolescent girls for developing PCOS

2.3 Phase II: Effectiveness of awareness program

Table 2: Mean, mean difference and $t$ value of pre-test and post-test scores of students on PCOS

$(\mathrm{n}=102)$

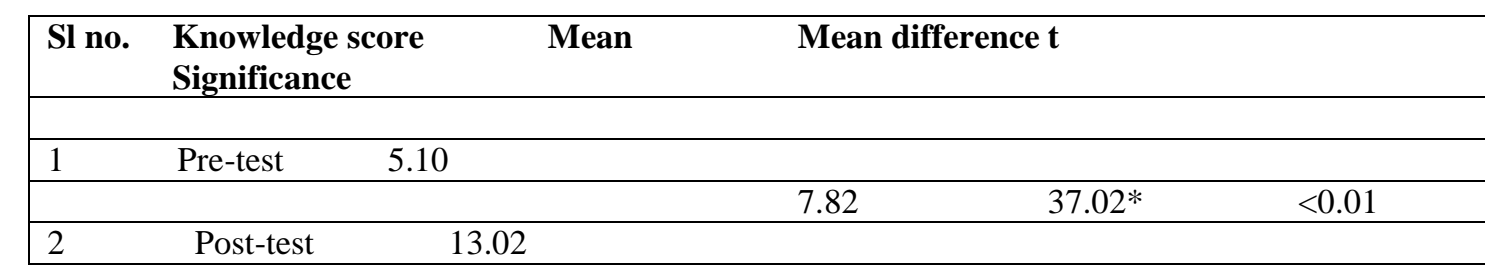

$* t(101)=37.02,<0.05$

The data presented in table 2 shows that mean difference of pre-test and post-test knowledge score was 7.82. In order to find the significant difference between two correlated means of pre-test and post-test knowledge score, paired $\mathrm{t}$ test was computed $(\mathrm{t}=37.02, \mathrm{p}<0.001)$. Statistically it was inferred that the awareness program was effective in improving the knowledge on PCOS.

2.4 Association between risk status and selected demographic variables

Table 3: Chi square values between risk status and socio-economic status $(\mathbf{n}=752)$

\begin{tabular}{|c|c|c|c|c|c|}
\hline $\begin{array}{l}\text { Variable } \\
\text { Income/month } \\
\text { In rupees }\end{array}$ & Low risk & Moderate risk & $\chi^{2}$ & df & p value \\
\hline$>10000$ & 155 & 29 & & & \\
\hline $5001-10000$ & 322 & 38 & 0.65 & 2 & 0.54 \\
\hline $3001-5000$ & 173 & 35 & & & \\
\hline \multicolumn{6}{|l|}{ Area of living } \\
\hline Urban & 77 & 12 & & & \\
\hline Rural & 573 & 90 & 0.98 & 1 & 0.13 \\
\hline $\begin{array}{l}\text { Fathers' } \\
\text { Educational st } \\
\text { Illiterate }\end{array}$ & & & & & \\
\hline Primary & 36 & 6 & & & \\
\hline High school & 306 & 47 & & & \\
\hline PUC & 226 & 38 & 0.69 & 5 & \\
\hline Graduate & 57 & 7 & & & $* 0.04$ \\
\hline Post-graduate & $\begin{array}{r}19 \\
3\end{array}$ & $\begin{array}{l}7 \\
2\end{array}$ & & & \\
\hline \multicolumn{6}{|l|}{ Mothers' } \\
\hline Illiterate & 43 & 4 & & & \\
\hline Primary & 368 & 69 & & & \\
\hline High school & 186 & 24 & 0.18 & 5 & $* 0.02$ \\
\hline PUC & 11 & 41 & & & \\
\hline Graduate & 1 & 5 & & & \\
\hline & 0 & - & & & \\
\hline \multicolumn{6}{|c|}{ Postgraduate } \\
\hline \multicolumn{6}{|c|}{ Fathers' occupation } \\
\hline Semiskilled & 273 & 48 & & & \\
\hline Professional & 210 & 31 & & & \\
\hline Business & 3 & 1 & 0.73 & 3 & 0.22 \\
\hline Unemployed & 160 & 21 & & & \\
\hline & 4 & 1 & & & \\
\hline
\end{tabular}


An exploratory survey to identify the adolescents with high risk for Polycystic Ovarian Syndrome ...

\begin{tabular}{llllll}
\hline Mothers' occupation & 80 & 11.99 & & & \\
Unskilled & 88 & 14 & & & \\
Semiskilled & 2 & 0.01 & 0.95 & 3 & $* 0.03$ \\
$\begin{array}{l}\text { Professional } \\
\text { Housewife }\end{array}$ & 480 & 74 & & & \\
& & & & & \\
Weight in Kgs & 331 & 51 & & \\
$30-45$ & 304 & 41 & 0.95 & 2 & 0.07 \\
$46-60$ & 15 & 2 & & & \\
$61 \&$ above & & & & \\
\hline
\end{tabular}

${ }^{*} \mathrm{p}<0.05$

Data presented in table 3 show that there is no significant association between risk status and income of the family ( $<<0.54)$, area of living $(\mathrm{p}<0.13)$ fathers' occupation $(\mathrm{p}<0.22)$, weight of the students $(\mathrm{p}<0.07)$ and association was seen between fathers' educational status $(p<0.04)$, mothers' educational status $(p<0.02)$ and mothers' occupation $(\mathrm{p}<0.03)$. Hence it was inferred that the risk status was independent of the selected variables like income of the family, area of living and fathers' occupation weight of the students.

\section{Discussion}

A bibliographic search was done to identify the usefulness of screening test to identify the adolescents with risk for PCOS. A cross sectional study was done in Sri Lanka to identify the prevalence of PCOS. The study findings support the present study findings as the total prevalence was $6.3 \%$ and $91.1 \%$ of women with oligo/amenorrhoea and/or hirsutisms were confirmed to have $\operatorname{PCOS}^{[3]}$.

An educational intervention study was carried out over a period of one year by Rao RS, et al., (2008) to determine the effectiveness of reproductive health education program among rural adolescent girls in Udupi Taluk, Karnataka. Seven hundred and ninety one rural girls in the age group of 16-19 years were included and educated regarding reproductive health. A significant increase in overall knowledge was observed regarding contraception, ovulation, first sign of pregnancy and fertilisation. The study clearly showed that educational intervention program could bring about a desirable change in knowledge among adolescent girls ${ }^{[4]}$.

\section{Conclusion}

Adolescents who are overweight or obese at the time of diagnosis should be encouraged to engage in a diet and exercise plan that will aid them in attaining and subsequently maintaining a healthy body weight and to regularize the hormonal cycle ${ }^{[6]}$. PCOS cannot be prevented or cured; it can be controlled, with varying degrees of success, with healthy lifestyle choices. Many women experience improvement in the signs and symptoms of PCOS if they maintain a healthy weight. Research indicates that even a moderate decrease in weight, as little as $5 \%$ from baseline, can improve rates of ovulation and conception by lowering androgen levels, as well as improve the insulin resistance associated with this disorder ${ }^{[7]}$.

\section{Acknowledgement}

The authors would like to thank all the participants for their willingness to participate in the study.

\section{References}

[1]. Azziz R, Carmina E, Dewailly D. Positions statement: criteria for defining polycystic ovary as a predominantly hyperandrogenic syndrome: An Androgen excess society guideline. J Clin Endocrinol Metab 2006 Dec 91:4237-45.

[2]. Kousta E, White DM. The prevalence of polycystic ovaries in women with infertility. HRJ of India 1999 April 90:2545-9.

[3]. Kumarapeli R, Seneviratne CN, Wijeyaratne RM.A Simple Screening Approach forAssessing Community Prevalence and Phenotype of Polycystic Ovary Syndrome in a Semi-urban Population in Sri Lanka. American Journal of Epidemiology 2007 Oct 10: 1093-99.

[4]. Rao RS, Lena A, Nair NS, Kamath V, Kamath A. Effectiveness of reproductive health education among rural adolescent girls: a school based intervention study in Udupi Taluk, Karnataka. Indian J Med Sci. 2008 Nov 62 (11) 439-43.

[5]. Ganie MA. Marwaha R. Aggarwal R. Singh S. High prevalence of polycystic ovarian syndrome (PCOS) characteristics in girls with euthyroid chronic lymphocytic thyroiditis: a case control study. European journal of endocrinology 2010 March 162:1117.

[6]. Timothy FK. PCOS prevalence estimated at 6\%: hirsuitism most common presentation. OB/GYN news 2002 August 15 (cited 2011 Jan). Available from: htpp://findarticles.com/p/search/?qa.

[7]. Elsenbruch S. Hahn S. Quality of life, psychosocial well satisfaction in women with polycystic ovary syndrome. Journal of clinical endocrinology 2003 Jan 94:1322-28. 